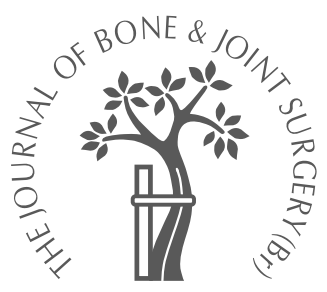

J.-P. Whittaker, G. Smith, N. Makwana, S. Roberts,

P. E. Harrison, P. Laing, J. B. Richardson

From The Robert Jones \& Agnes Hunt Orthopaedic Hospital, Oswestry, England

J.-P. Whittaker, MRCS, Specialist Registrar G. Smith, MRCS, Research Fellow

N. Makwana, FRCS Orth,

Consultant Orthopaedic

Surgeon

P. Laing, FRCS, Consultant

Orthopaedic Surgeon

S. Roberts, PhD, Clinical

Scientist

Centre for Spinal Studies

P. E. Harrison, MMedSci,

Clinical Scientist

Arthritis Research Centre

J. B. Richardson, MD

FRCS, Professor of

Orthopaedics

Institute of Orthopaedics

Robert Jones \& Agnes Hun

Orthopaedic Hospital NHS

Trust, Oswestry, Shropshire

SY10 7AG, UK.

Correspondence should be sent to Dr J. P. Whittaker at 99

Harwoods Lane, Rossett,

Flintshire LL12 0EU, UK;

e-mail:

jpwhittaker@onetel.com

(C)2005 British Editorial

Society of Bone and

Joint Surgery

doi:10.1302/0301-620X.87B2.

$15376 \$ 2.00$

$J$ Bone Joint Surg [Br]

2005;87-B:179-83.

Received 4 February 2004;

Accepted after revision

24 May 2004

\section{Early results of autologous chondrocyte implantation in the talus}

There are many surgical options for the treatment of symptomatic osteochondral lesions of the talus. ${ }^{1-10}$ Smaller defects may cause no symptoms, although larger defects may cause pain, swelling, instability and later progression to secondary osteoarthritis. ${ }^{1,2}$ Methods of treatment have included debridement either in isolation or combined with Kirschner-wire drilling $^{3,4}$ or microfracture ${ }^{5}$ of subchondral bone. These have conventionally been used for lesions less than $1 \mathrm{~cm}^{2}$ in size with the intention of recruiting pluripotent stem cells, but they have often led to a fibrocartilaginous repair. ${ }^{11,12}$ Techniques designed to restore hyaline cartilage, particularly for larger osteochondral lesions, include mosaicplasty and autologous chondrocyte implantation (ACI). Mosaicplasty for the treatment of osteochondral talar lesions has been reported ${ }^{6,7}$ to have good results, although pain at the donor site has been reported. ACI pioneered by Brittberg et $\mathrm{al}^{13}$ and Peterson et $\mathrm{al}^{14}$ for the treatment of full-thickness cartilage defects in the knee has had encouraging results. However, few studies have reported its use in the treatment of talar osteochondral defects. ${ }^{12,13}$ Our study reports the use of ACI for full-thickness, large $\left(>1 \mathrm{~cm}^{2}\right)$ contained defects of the talus, including the morbidity at the donor site up to four years after treatment.

ACI is a two-stage procedure. The first involves the isolation, culture and proliferation of chondrocytes. ${ }^{15}$ Arthroscopy of the knee is performed through standard anterolateral and anteromedial portals under tourniquet control. Specimens of cartilage (approximately 270 $\mathrm{mg}$ ) are taken using a 5-mm gouge from the trochlea or superolateral femoral ridge, from a part of the knee with low weight-bearing. The biopsy material is then transported to the laboratory for chondrocyte culture. This takes approximately three weeks. The second stage involves implantation of the chondrocytes.

\section{Patients and Methods}

We studied ten stable ankles in ten patients with isolated osteochondral defects of the talus. The seven men and three women had a mean age of 42 (18 to 62) years. The lesions were on the medial aspect of the talus in six (five traumatic) and lateral in four (two traumatic). The lesions (Fig. 1) had a mean area of $1.95 \mathrm{~cm}^{2}$ (1 to 4 ) as measured intra-operatively. The mean weight of the cartilage harvested was $256 \mathrm{mg}$ (182 to 420), allowing a mean cell culture of 5.1 million (1.5 to 7.5 ) chondrocytes.

All ten patients received ACI for disabling symptoms of pain and swelling for a median period of two years (Table I). Six had had surgery before referral. These operations included three ankle arthroscopies with debridement alone, two with Kirschner-wire drilling and debridement, and one arthroscopic washout. 
Table I. Details of the ten patients

\begin{tabular}{|c|c|c|c|c|c|c|c|c|}
\hline Case & Gender & $\begin{array}{l}\text { Age } \\
\text { (yrs) }\end{array}$ & Aetiology & Site of lesion & Side & $\begin{array}{l}\text { Duration of } \\
\text { symptoms (yrs) }\end{array}$ & $\begin{array}{l}\text { Number of previous } \\
\text { operations }\end{array}$ & Previous surgery \\
\hline 1 & M & 37 & Trauma & Medial & $\mathrm{R}$ & 2 & 1 & Debridement and drilling \\
\hline 2 & M & 47 & Trauma & Medial & $\mathrm{L}$ & 2 & 2 & $\begin{array}{l}\text { Debridement and drilling } \\
\text { Arthroscopic washout }\end{array}$ \\
\hline 3 & M & 47 & Trauma & Medial & $\mathrm{L}$ & 2 & 2 & $\begin{array}{l}\text { Debridement } \\
\text { Bone graft }\end{array}$ \\
\hline $4^{*}$ & $\mathrm{~F}$ & 36 & Trauma & Medial & $\mathrm{R}$ & 3 & 0 & None \\
\hline $5^{*}$ & $\mathrm{~F}$ & 47 & Trauma & Medial & $\mathrm{R}$ & 2 & 0 & None \\
\hline 6 & M & 62 & Idiopathic & Medial & $\mathrm{R}$ & 2 & 0 & None \\
\hline 7 & M & 37 & Trauma & Anterolateral & $\mathrm{L}$ & 0.75 & 1 & Debridement \\
\hline 8 & $\mathrm{~F}$ & 47 & Idiopathic & Anterolateral & $L$ & 1.50 & 0 & None \\
\hline 9 & M & 40 & Trauma & Centrolateral & $\mathrm{L}$ & 5 & 2 & $\begin{array}{l}\text { Excision of fragment } \\
\text { Debridement }\end{array}$ \\
\hline $10 *$ & M & 18 & Idiopathic & Anterolateral & $\mathrm{L}$ & 3 & 1 & Arthroscopic washout \\
\hline
\end{tabular}

* bone graft and $\mathrm{ACl}$

One patient had had an open excision of the osteochondral fragment and one patient had had a bone graft to the defect.

The ACI procedures were performed under general anaesthesia and tourniquet control. The osteochondral defects were approached through a medial or lateral malleolar osteotomy and debrided as far as the surrounding normal cartilage until subchondral bone was exposed. One patient had reconstruction of a subchondral talar cyst with retrograde bone grafting through the talar neck. Two required reconstruction of intra-articular osseous defects using a sandwich technique of bone grafting of the base of the defect with a separate periosteal covering flap, hence separating the implanted chondrocytes from the bone graft. The defect was covered by a periosteal flap taken from the distal tibia and secured with sutures (6-O vicryl) and fibrin glue, with the deep cambium layer facing the subchondral bone plate. The seal of periosteal patch was tested and the chondrocytes injected beneath it. The osteotomy was then reduced and fixed. Osteochondral lesions extending over a medial or lateral talar edge were repaired with the periosteal patch secured over the talar edge. Restoration of ankle congruence on closure allowed the fluid repair to adopt a reciprocal shape to the articular surface of the tibia.

Rehabilitation was divided into four phases. Phase I (immediately post-operatively until the osteotomy had united) involved non-weight-bearing with physiotherapy to achieve a plantigrade position and active and passive exercises. During phase II (three to six weeks post-operatively) weight-bearing was increased. Between six weeks and six months, in phase III, activities were increased and included swimming and cycling. Lastly, running was introduced in phase IV.

The clinical outcome was assessed using a combination of examination, patient satisfaction (subjectively assessed on a scale from 'extremely pleased' to 'much worse'), and a modification of the ankle score of Mazur, Schwartz and Simon ${ }^{16}$ and the knee score of Tegner and Lysholm, ${ }^{17}$ taken both pre- and post-operatively at three months and annually thereafter. The scoring assessments were completed by patients before clinical examination.

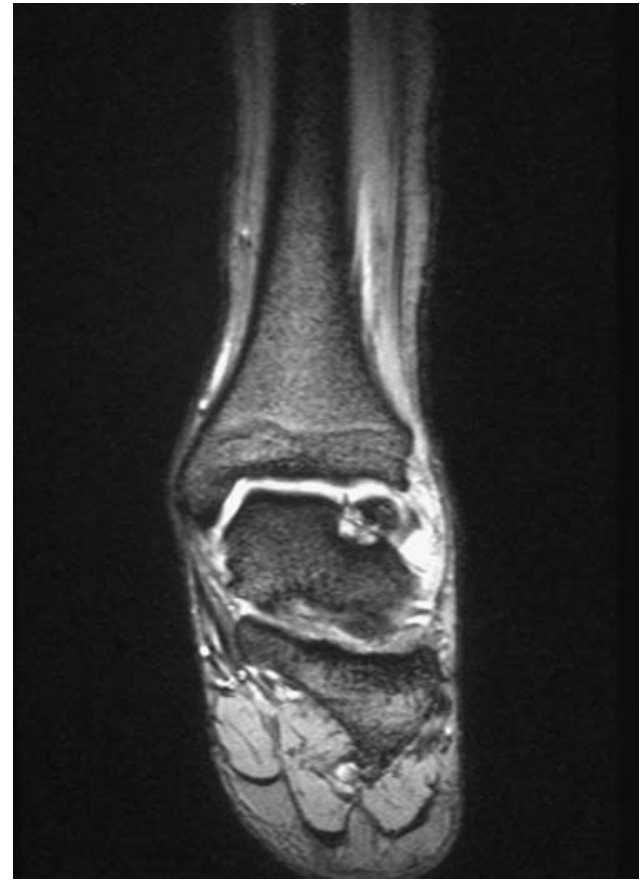

Fig. 1

Case 10. MR scan (T2-weighted) showing a typical talar osteochondral defect on the lateral side.

Arthroscopy was undertaken at approximately 12 months after surgery. The site of the ACI was assessed with a hook for appearance, stiffness and integration. The gross appearance was considered to be acceptable if the transplanted tissue was level and integrated with the surrounding articular cartilage. Biopsies were taken when possible from the centre of the grafted region, although this was difficult in some because of limited access. Histological examination was performed on nine biopsies of cartilage and underlying bone $(1.8 \mathrm{~mm}$ in diameter) taken from nine patients at 12 months and in one patient at 40 months after operation. Sections stained by haematoxylin and eosin 
Table II. Details of the lesions and outcomes

\begin{tabular}{|c|c|c|c|c|c|c|c|c|}
\hline \multirow[b]{2}{*}{ Case } & \multirow[b]{2}{*}{$\begin{array}{l}\text { Size of } \\
\text { lesion }\left(\mathrm{cm}^{2}\right)\end{array}$} & \multicolumn{2}{|c|}{ Knee score (0 to 100$)$} & \multicolumn{3}{|c|}{ Ankle score (0 to 90$)$} & \multirow[b]{2}{*}{$\begin{array}{l}\text { Post-operative } \\
\text { satisfaction }\end{array}$} & \multirow[b]{2}{*}{$\begin{array}{l}\text { Follow-up } \\
\text { (mths) }\end{array}$} \\
\hline & & Pre-operative & $\begin{array}{l}\text { Post-operative } \\
\text { at } 1 \mathrm{yr}\end{array}$ & Pre-operative & $\begin{array}{l}\text { Post-operative } \\
\text { at } 1 \mathrm{yr}\end{array}$ & $\begin{array}{l}\text { Post-operative at } \\
\text { final follow-up }\end{array}$ & & \\
\hline 1 & 4.0 & 100 & 100 & 51 & 63 & 54 & Extremely pleased & 54 \\
\hline 2 & 2.0 & 100 & 87 & 54 & 81 & 86 & Extremely pleased & 37 \\
\hline 3 & 2.0 & 90 & 74 & 44 & 64 & 75 & Pleased & 24 \\
\hline 4 & 1.0 & 100 & 100 & 50 & 44 & 44 & No different & 30 \\
\hline 5 & 1.9 & 100 & 95 & 41 & 88 & 88 & Extremely pleased & 13 \\
\hline 6 & 1.0 & 100 & 57 & 35 & 74 & 74 & Extremely pleased & 13 \\
\hline 7 & 2.3 & 100 & 88 & 58 & 84 & 84 & Pleased & 26 \\
\hline 8 & 1.9 & 100 & 93 & 61 & 71 & 71 & Pleased & 12 \\
\hline 9 & 1.4 & 100 & 91 & 47 & 73 & 73 & Extremely pleased & 12 \\
\hline 10 & 1.3 & 100 & 100 & 68 & 88 & 88 & Pleased & 12 \\
\hline
\end{tabular}

were assessed using standard and polarised light microscopy. ${ }^{18,19}$

\section{Results}

Clinical. Nine (90\%) patients were 'pleased' or 'extremely pleased' with the operation, a result which was maintained at four years. Assessment using a modified Mazur ankle score gave a mean pre-operative score of 51/90 (35 to 68), with improvement at one year to a mean of 73/90 (44 to 88). The ankle score continued to show an improvement at a mean of 23 months (12 to 54) with a mean score of 74/90 (44 to 88 ). This improvement was statistically significant (two-tailed, $\mathrm{p}=0.0005$ ). The mean range of movement post-operatively at one year was $30^{\circ}$ to $40^{\circ}$ of plantar flexion and $8^{\circ}$ to $15^{\circ}$ of dorsiflexion, which was unchanged from the pre-operative state. There was no association between outcome and duration of symptoms, previous surgical debridement with or without drilling or the cause of the lesion. One patient, whose satisfaction score was 'no different than before the operation' had the most extensive osteochondral defect. The medial chondral defect measured $1 \mathrm{~cm}^{2}$, but a large cyst extended from this to the subtalar joint. Initially post-operatively, the patient improved with an increase in the ankle score of 28 points at eight months. Subsequently, the symptoms recurred with reformation of the cyst. All malleolar osteotomies united clinically and radiologically. One patient had a superficial infection of the ankle. This was treated with flucloxacillin and settled.

The Lysholm score of the knee from which the cartilage had been harvested was normal in three patients at a mean follow-up of 23 months. The remaining seven patients had a reduced score, with a mean reduction of 15 points at 12 months. The results are summarised in Table II.

Arthroscopic findings. Nine patients had a repeat ankle arthroscopy at a mean of 13 months (12 to 19) after operation. Macroscopically, the defects in all patients were filled (Fig. 2). One did not have a complete assessment of the site of the graft because of technical difficulty in a tight ankle. Eight patients had complete marginal integration; two had incomplete marginal integration with the surrounding articular cartilage. Two patients had a graft which was

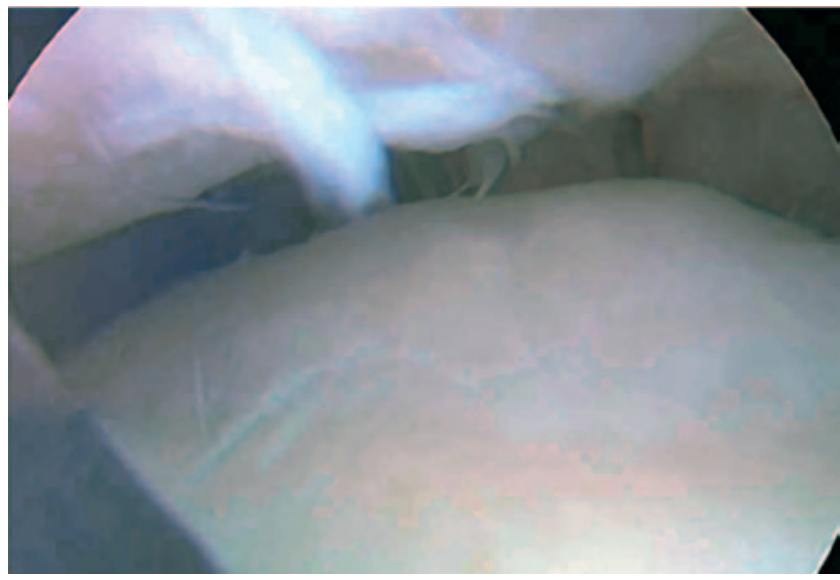

Fig. 2a

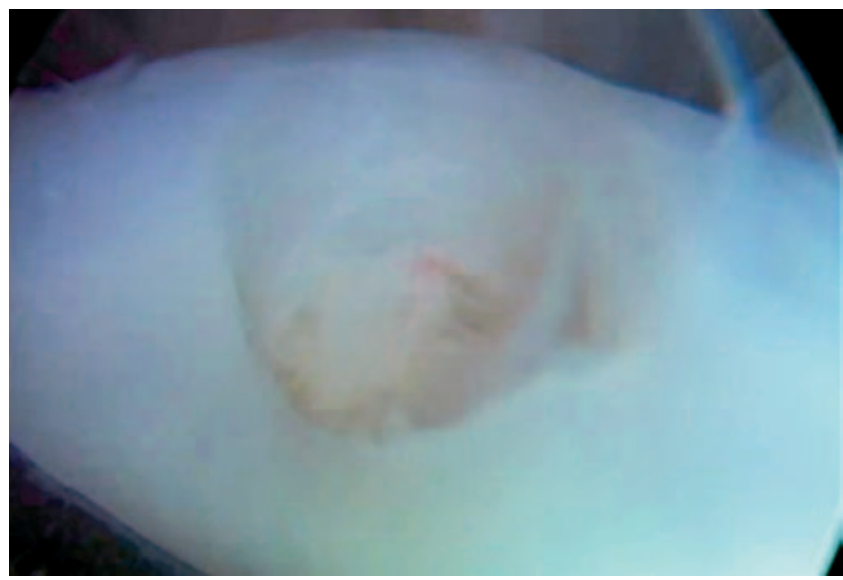

Fig. 2b

Case 10. Arthroscopy showing a lateral talar osteochondral defect a) preoperatively $\left(1.3 \mathrm{~cm}^{2}\right)$ and b) at 12 months after $\mathrm{ACl}$ with a smooth graft site which is white in colour and slightly raised and softer than the surrounding cartilage.

raised compared with the level of the surrounding cartilage and four had a firm surface on probing with six having a surface slightly softer than the surrounding cartilage. Three patients had an area of synovitis in the ankle. 


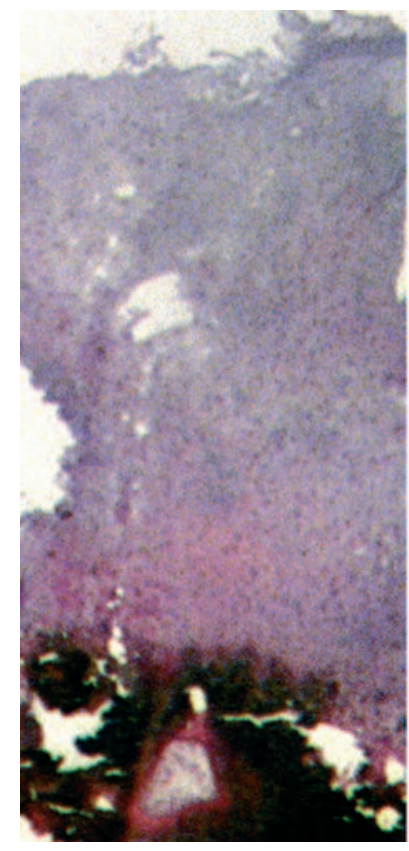

Fig. 3a

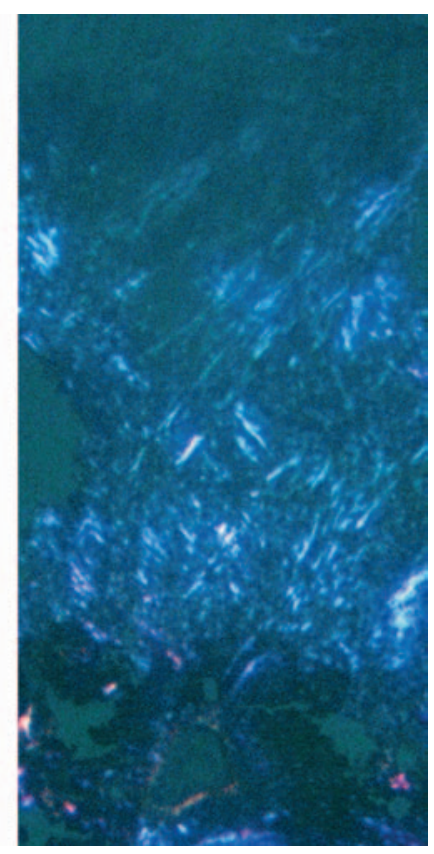

Fig. 3b

Case 5, 13 months after $\mathrm{ACl}$. Photomicrographs of fibrocartilage throughout the biopsy a) by light microscopy (haematoxylin and eosin) and b) by polarised light (showing a random organisation of collagen typical of fibrocartilage) (x60).

Histological findings. Full-thickness biopsies of the treated region down to and including bone were obtained in five of six patients. Other biopsies were incomplete because of restriction of space and difficult access, which also resulted in some of the biopsies being oblique rather than perpendicular to the articulating surface. Hyaline cartilage was present in some regions of two biopsies, and the three remaining samples being fibrocartilage (Figs 3 and 4). Fibrous tissue was not present in any samples.

\section{Discussion}

Debridement with or without drilling and microfracture has produced good results ${ }^{3-5}$ with a good or excellent outcome in approximately $80 \%$ of cases $^{3}$ and fibrocartilaginous repair tissue in most. When these treatments fail to provide long-term symptomatic relief, further arthroscopic surgery has poor results ${ }^{4}$ and hence open surgery is necessary. This involves a larger surgical exposure, including arthrotomy and malleolar osteotomy. Osteotomies, particularly on the medial side, can cause morbidity if complicated by nonunion or malunion. ${ }^{5}$ Mosaicplasty has the advantage of immediate transplantation of articular cartilage, which can deal with large osteochondral lesions, although it is recognised that there is a dead space between the cylindrical grafts and the recipient defect, which may integrate with fibrocartilaginous repair tissue. ${ }^{19-21}$ ACI produces a repair which is well contoured to the surrounding articular surface and may reproduce a depth of repair tissue which resembles the native articular surface more closely

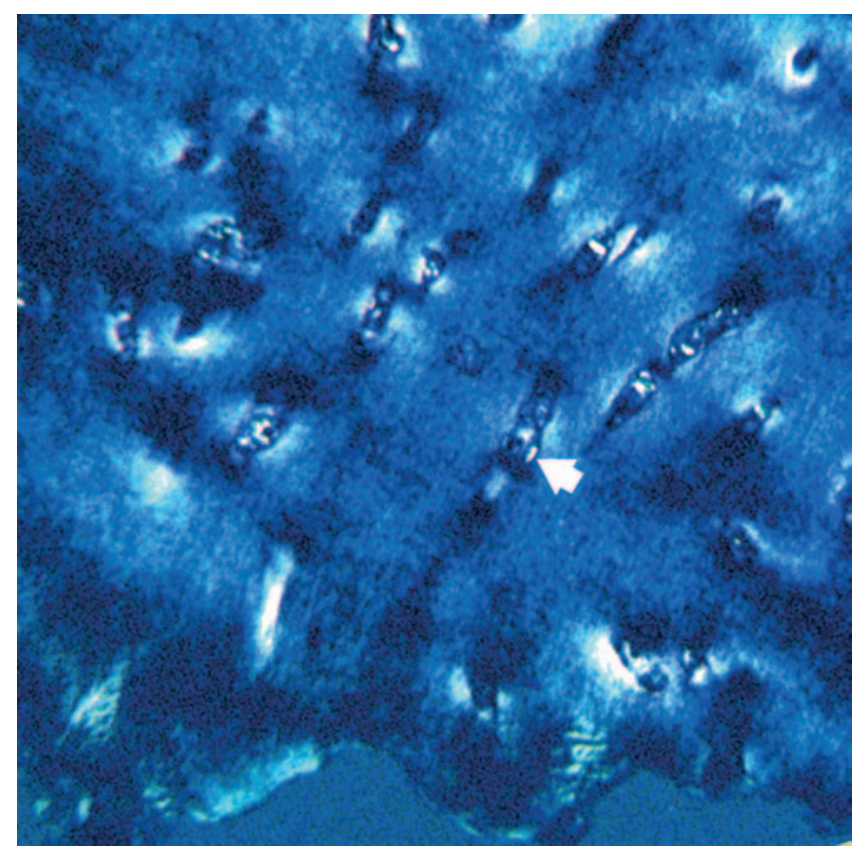

Fig. 4

Case 2, 13 months after $\mathrm{ACl}$. Photomicrography of hyaline cartilage in the lower region of a biopsy, viewed by polarised light showing cells (arrow) interspersed within the amorphous glass-like matrix (toluidine blue $\times 225$ ).

than mosaic plugs taken from the knee, in which the depth of articular cartilage exceeds that of the talus.

Our series of patients who had ACI has been formally assessed with respect to both donor and recipient sites over time using objective and subjective scores which have not been a feature of previous studies. Our early results suggest that a large osteochondral lesion can be treated by ACI, leading to clinical improvement. Factors reportedly associated with a poorer outcome include duration of symptoms, ${ }^{4}$ previous arthroscopic debridement with or without drilling, ${ }^{1,4}$ atraumatic lesions, ${ }^{2}$ medial lesions and cystic changes. ${ }^{1,4}$ We found no association between outcome and previous surgery, cause of the lesion or duration of symptoms. Our only dissatisfied patient had a medial osteochondral lesion with severe cystic changes. Although histologically not all biopsies have revealed hyaline-like tissue, these represent a 'snapshot' of a dynamic repair process. It has been shown that type-II collagen is present in the fibrocartilaginous repair tissue formed by $\mathrm{ACI}^{22}$ and this has been implicated in the regeneration of articular cartilage. It has been suggested by Roberts et $\mathrm{al}^{19}$ that "initial cartilage repair is more fibrocartilaginous in nature but may remodel with time to form hyaline cartilage, possibly in response to loading". We believe that ACI has shown encouraging results in the treatment of localised, contained large cartilage defects of the talus with improvements also seen in those patients refractory to previous treatments.

Our study has also provided an opportunity to assess the morbidity of the cartilage harvested as a cell source for 
ACI. There is a limited morbidity which presently appears to show a return of the pre-operative Lysholm knee scores in one-third of patients by 12 months. Trials are needed, particularly a multicentre randomised, controlled study. We suggest that the short-term results of talar ACI are good, despite some morbidity at the donor site.

We acknowledge and thank our colleagues B. Ashton, K. Ashton, S. Turner, A Bailey, A. Biggs and A. Jones for their support.

No benefits in any form have been received or will be received from a com mercial party related directly or indirectly to the subject of this article.

\section{References}

1. Bauer $\mathbf{M}$, Jonsson $\mathbf{K}$, Linden B. Osteochondritis dissecans of the ankle: a 20 -year follow-up study. J Bone Joint Surg [Br] 1987;69-B:93-6.

2. Canale ST, Belding RH. Osteochondral lesions of the talus. J Bone Joint Surg [Am] 1980;62-A:97-102.

3. Tol JL, Struijs PAA, Bossuyt PMM, Verhagen RA, van Dijk CN. Treatment strategies in osteochondral defects of the talar dome: a systematic review. Foot Ankle Int 2000;21:119-26

4. Robinson DE, Winson G, Harries WJ, Kelly AJ. Arthroscopic treatment of osteochondral lesions of the talus. J Bone Joint Surg [Br] 2003;85-B:989-93.

5. Navid DO, Myerson MS. Approach alternatives for treatment of osteochondral lesions of the talus. Foot Ankle Clin 2002;7:635-49.

6. Hangody L, Kish G, Modis L, et al. Mosaicplasty for the treatment of osteochondritis dissecans of the talus: two to seven year results in 36 patients. Foot Ankle Int 2001;22:552-8.

7. Gautier E, Kolker D, Jakob RP. Treatment of cartilage defects of the talus by autologous osteochondral grafts. J Bone Joint Surg [Br]2002;84-B:237-44.

8. Giannini S, Buda R, Grigola B, Vannini F. Autologous chondrocyte transplantation in osteochondral lesions of the ankle joint. Foot Ankle Int 2001;22:513-17.
9. Petersen L, Brittberg M, Lindahl A. Autologous chondrocyte transplantation of the ankle. Foot Ankle Clin 2003;8:291-303.

10. Kumai T, Takaura Y, Higashiyama I, Tamai S. Arthroscopic drilling for the treatment of osteochondral lesions of the talus. J Bone Joint Surg [Am] 1999;81-A 1229-33.

11. Ficat RP, Ficat C, Gedeon P, Toussaint JB. Spongialization: a new treatment for diseased patella. Clin Orthop 1979;144:74-83.

12. Johnson LL. Arthroscopic abrasion arthroplasty. Clin Orthop 2001;391(Suppl): 306-17

13. Brittberg M, Lindahl A, Nilsson A, et al. Treatment of deep cartilage defects in the knee with autologous chondrocyte transplantation. N Eng J Med 1994;331:889-95

14. Peterson L, Minas T, Brittberg M, et al. Two- to 9 -year outcome after autologous chondrocyte transplantation of the knee. Clin Orthop 2000;374:212-34.

15. Harrison PE, Ashton IK, Johnson WEB, et al. The in vitro growth of human chondrocytes. Cell Tissue Banking 2000;1:255-60.

16. Mazur JM, Schwartz E, Simon SR. Ankle arthrodesis: long-term follow-up with gait analysis. J Bone Joint Surg [Am] 1979;61-A:964-75.

17. Tegner Y, Lysholm J. Rating systems in the evaluation of knee ligament injuries. Clin Orthop 1985;198:43-9.

18. Mainil-Varlet $\mathbf{P}$, Aigner T, Brittberg M, et al. Histological assessment of cartilage repair: a report by the histological endpoint committee of the international cartilage repair society (ICRS). J Bone Joint Surg [Am]2003;85-A(Suppl 2):45-57.

19. Roberts S, McCall IW, Darby AJ, et al. Autologous chondrocyte implantation fo cartilage repair: monitoring its success by magnetic resonance imaging and histology. Arthr Res Ther 2003;5:60-74.

20. Matsusue Y, Yamamuro T, Hama H. Arthroscopic multiple osteochondral trans plantation to the chondral defect in the knee associated with anterior cruciate ligament disruption. Arthroscopy 1993;9:318-21.

21. Lindholm TS, Osterman K, Kinnunen P, Lindholm TC, Osterman HK. Reconstruction of the joint surface using osteochondral fragments: an experimental and clinica study. Scand J Rheumatol Supp/ 1982;44:5-46.

22. Briggs TWR, Mahroof S, David LA, et al. Histological evaluation of chondral defects after autologous chondrocyte implantation of the knee. J Bone Joint Surg [Br] 2003:85-B:1077-83. 